\title{
Drug Abuse and Addiction Effects on Human Body
}

\author{
Dr. Ibuathu C. Njati, Ph.D \\ (Chairman ADSA Committee-MUST)
}

\begin{abstract}
Drug and substance abuse has been of great concern to institutions, families, employers and employees alike. However, these concerns have to be addressed through dissemination of relevant knowledge about drug use and abuse. Children, workers and managers need to know and understand the dangers of drug and substance abuse at home and work places. Drug and substance abuse weakens an individual working stability and by extension weakens firms output.
\end{abstract}

Key words:-Drug abuse, addiction, substance abuse, drug health problems

What is a drug?

A drug is chemical substance which when taken changes the functioning of the body and the mind. Drugs are chemicals. Different drugs, because of their chemical structures, can affect the body in different ways. In fact, some drugs can even change a person's body and brain in ways that last long after the person has stopped taking drugs, maybe even permanently.

What is drug use?

Using a drug for its intended purpose, e.g. use of anti-malarial tablets to treat malaria, panadol to relieve pain. Depending on the drug, it can enter the human body in a number of ways such as:

i. injection,

ii. inhalation,

iii. ingestion.

The method of how it enters the body impacts on how the drug affects the person. For example: injection takes the drug directly into the blood stream, providing more immediate effects; while ingestion requires the drug to pass through the digestive system, delaying the effects.

\section{What is drug abuse?}

Drug abuse is the improper use of drugs, e.g. taking piriton to sleep instead of using it to treat allergy, sniffing glue instead of using it as an adhesive. Most abused drugs directly or indirectly target the brain's reward system by flooding the circuit with dopamine. Dopamine is a neurotransmitter present in regions of the brain that regulate movement, emotion, cognition, motivation, and feelings of pleasure. When drugs enter the brain, they can actually change how the brain performs its jobs. These changes lead to compulsive drug use, the hallmark of addiction (World Drug Report, 2014).

Drugs and substances abused in Kenya today include:

(NACADA, (2012) identifies the followings drugs are abused in Kenya today.

1. Alcohol

2. Tobacco

3. Miraa/ khat

4. Marijuana

5. Inhalants and Solvents

6. Heroin

7. Cocaine

8. Prescription Drugs - including sex enhancement drugs

Substance abuse among the young people in learning institutions has endangered their lives. A report by the National Agency for Campaign against Drug Abuse (NACADA, 2012); indicates that the majority of students in all levels of education still abuse substances and are likely to destroy their lives before they become adults or even drop out of school. This is causing a lot of concern as the vice, indeed, has been identified as a major cause of some of the problems experienced in learning institutions in Kenya in the recent past (Maithya, 2012 \& Muchemi, 2013).

\section{CAUSES OF DRUG ABUSE IN KENYA}

1. Peer influence

2. Low self-esteem 
3. Media influence (TV, magazines, internet)

4. Rebellion against parents, teachers, religion etc

5. Curiosity

6. Lack of knowledge of drugs

7. Poor role models.

8. Frustrations from home, school, body changes etc

9. Inability to achieve goals set thus feeling like a failure

10. False ideas and perceptions. e.g. bhang enhances academic performance.

In addressing these causes, while launching the $2^{\text {nd }}$ national conference on Drug and Substance Abuse: $A$ Call for Action, organized by NACADA in 2013, to formulate measures to curb drug abuse; the President of Kenya, Hon. Uhuru Kenyatta directed the National Treasury to allocate more resources for prevention and control of alcohol and drug abuse. In addition, the treasury was advised to seek innovative ways of securing funding to increase NACADA's resource base in the fight against drug and substance abuse in the country, particularly among the young people both in and out of learning institutions (Standard Newspaper, June, 2014).

\section{EFFECTS OF DRUG ABUSE IN KENYA}

1. Poor memory

2. Reduced reasoning capacity

3. Truancy and poor performance in school, sports and other activities.

4. Poor concentration

5. Dropping out of school.

6. Suspension and expulsion from schools.

7. Risky sexual behaviour leading to early pregnancy \& HIV/AIDS

8. Crimes like theft, violence, rape, incest, bestiality (sex with animals) leading to legal implications.

9. Poor health

10. Personal neglect

11. Withdrawal and isolation from society

12. Being shunned by the society.

13. Personal guilt

14. Poor relations with parents, teachers, siblings and peers.

15. Physical and psychological addiction.

16. Overdose of drugs can lead to DEATH.

According to the World Drug Report (2014), drug users like other people, seek approval for their behaviour from their peers whom they attempt to convince to join their habit as a way of seeking acceptance. Studies carried out by Maithya (2012) and Chesang (2013) on drug abuse among young people showed that there is a significant relationship between the subjects' drug-using behaviour and the involvement of their friends in drugs. In their view, if an adolescent associates with other adolescents who use drugs, the risk of involvement with drugs is further increased. The studies also argue that peer pressure encourages youth to use substances under the false impression that some drugs stimulate appetite for food, increase strength and give wisdom as well as courage to face life.On the other hand, a survey report released by the National Agency for Campaign against Drug Abuse (NACADA, 2012) authority in Kenya, shows that young people, students included between 10 and 24 years whose parents use or sell alcohol and other drugs are likely to abuse these substances themselves. At times, youth, including students, who sell such substances on behalf of their parents, are themselves exposed to substance abuse in due course.

\section{DRUG HEALTH PROBLEMS}

The impact of drug abuse and dependence can be far-reaching, affecting almost every organ in the human body. Drug abuse can:

- Weaken the immune system, increasing susceptibility to infections.

- Cause cardiovascular conditions ranging from abnormal heart rate to heart attacks. Injected drugs can also lead to collapsed veins and infections of the blood vessels and heart valves.

- Cause nausea, vomiting and abdominal pain.

- Cause the liver to have to work harder, possibly causing significant damage or liver failure.

- Cause seizures, stroke and widespread brain damage that can impact all aspects of daily life by causing problems with memory, attention and decision-making, including sustained mental confusion and permanent brain damage. 
- Produce global body changes such as breast development in men, dramatic fluctuations in appetite and increases in body temperature, which may impact a variety of health conditions.

\section{IV. $\quad$ EFFECTS ON THE BRAIN}

Although initial drug use may be voluntary, drugs have been shown to alter brain chemistry, which interferes with an individual's ability to make decisions and can lead to compulsive craving, seeking and use. This then becomes a substance dependency.

- All drugs of abuse - nicotine, cocaine, marijuana, and others - effect the brain's "reward" circuit, which is part of the limbic system.

- Drugs hijack this "reward" system, causing unusually large amounts of dopamine to flood the system.

- This flood of dopamine is what causes the "high" or euphoria associated with drug abuse.

\section{Behavioural Problems}

- Paranoia

- Aggressiveness

- Hallucinations

- Addiction

- Impaired Judgment

- Impulsiveness

- Loss of Self-Control

In spite of the measures taken by the government to curb drug abuse, the practice is still widespread in schools and institutions of higher learning. A report appearing on TV, K24 channel on 13th July, 2014 revealed that a 16 year old male student in a secondary school in Nyeri County died after a drinking alcohol in a bar. Additionally, another story by the Nation Media team, in the Daily Nation Newspaper July 15th 2014, indicates that two university students were among 21 brew victims who died after consuming adulterated spirits in Eldoret County. As a result, Uasin Gishu County Commissioner banned the sale of spirits indefinitely. This means that drug and substance abuse among students in Kenya has become a serious problem that affects all the people in the country, and especially students. It is in view of this background that the current study was carried out.

Reports on the impact of substances abuse on academic activities indicate that it interferes with physiological, psychological and emotional functioning. Among the problems recorded are impaired memory and other intellectual faculties, and tracking inability in sensory and perceptual functions (Agrawal \&Dick, 2008). Further, the habit creates preoccupation with acquiring the substances, adverse psycho-pathetic complications and social development. This may lead to truancy, lack of concentration on studies among others (Eisenstein, 2005). Reduced cognitive efficiency leads to poor academic performance and thus resulting in decreased self-esteem. This contributes to instability in an individuals' sense of identity, which in turn, is likely to contribute to further substance abuse, thus creating a vicious circle (Hawkins, Catalano \& Miller, 1992; Eisenstein, 2005). Other studies have expounded that it is not only those who abuse substances that are affected. Students who abstain frequently suffer the second hand effects from the behaviour of other students who abuse psychoactive substances (INCB, 2006).

\section{REFERENCES}

[1] Agrawal, A. \& Dick, D. (2008). Are there Genetic Influences on Addiction? Evidence from Family Adoption and twin Studies Addiction, 103(7):1069-1081 Alcohol related deaths in the UK: Statistics on Drugs Misuse [NS]. Office for National Statistics in the United Kingdom, (2013) http://www.hscic.gov.uk/catalogue/PUBI 2994.

[2] Boudah, D. J. (2011). Conducting Educational Research: Guide to Completing a Major Project: East Carolina University: Sage Publications Inc.

[3] Chesang, R. (2013). Drug Abuse Among the Youth in Kenya...http:/www.ijstr.org/finalprint/june2013/Drug-Abuse-Among-The- Youth-In-Kenya.Pdf

[4] Eisenstein, E. (2005). Youth and Drugs in Brazil: Social Imbalance and Health Risks. W.H.O. Geneva.

[5] Hawkins, J.D, Catalano, R.F. \& Miller, J.Y. (1992). "Risk and Protective Factors for Other Drug Problems in Adolescence and Early Adulthood: Implications for Substance Abuse Prevention". In Psychological Bulletin, 112 (1): 64-105.

[6] International Narcotics Control Board (INCB, 2006). The Impact of Drug Abuse on Crime and Violence at the Community Level...http://www.highbeam.com>.

[7] Kuppin, S. \& Carpiano, R. (2006). Public conceptions of serious mental illnesses and substance abuse, their causes and treatments: findings from the 1996 General Social Survey. American Journal of Public Health, 96:1766-1771. 
[8] Maithya, R. (2012). Drug Abuse in Secondary Schools in Kenya: Developing A Programme for Prevention and Intervention.LAP Lambert Academic Publishing. ISBN-10: 365919378X. ISBN-13:9783659193781.

[9] Muchemi, R. (2013). Drug and Substance abuse among Youth in the Informal Settlements ISSN: 22016333 (Print) ISSN: 2201-6740 (Online) www.ijern.com 642 within Nairobi: A Paper presented at NACADA Conference, Kenya, 2013.

[10] Mugenda, A.G. and Mugenda, O. M. (2012). Research Methods Dictionary. Nairobi, Kenya: Applied Research \& Training Services.

[11] NACADA, (2012). Report on Rapid Situation Assessment of Drug and Substance abuse in Kenya. Nairobi. Government Printer Word Drug Report, (2014).United Nations Publication, Sales No. E.14. X17, Vienna. Austria 